\title{
Age and sex based genetic locus heterogeneity in type 1 diabetes
}

\author{
Andrew D Paterson, Arturas Petronis
}

\begin{abstract}
Background-Two genome scans for susceptibility loci for type 1 diabetes using large collections of families have recently been reported. Apart from strong linkage in both studies of the HLA region on chromosome $6 \mathrm{p}$, clear consistent evidence for linkage was not observed at any other loci. One possible explanation for this is a high degree of locus heterogeneity in type 1 diabetes, and we hypothesised that the sex of affected offspring, age of diagnosis, and parental origin of shared alleles may be the bases of heterogeneity at some loci.

Methods-Using data from a genome wide linkage study of 356 affected sib pairs with type 1 diabetes, we performed linkage analyses using parental origin of shared alleles in subgroups based on (1) sex of affected sibs and (2) age of diagnosis.

Results-Among the results obtained, we observed that evidence for linkage to IDDM4 on chromosome 11q13 occurred predominantly from opposite sex, rather than same sex sib pairs. At a locus on chromosome $4 q$, evidence for linkage was observed in sibs where one was diagnosed above the age of 10 years and the other diagnosed below 10 years of age.

Conclusions-We show that heterogeneity tests based on age of diagnosis, sex of affected subject, and parental origin of shared alleles may be helpful in reducing locus heterogeneity in type 1 diabetes. If repeated in other samples, these findings may assist in the mapping of susceptibility loci for type 1 diabetes. Similar analyses can be recommended in other complex diseases.
\end{abstract}

(f Med Genet 2000;37:186-191)

Keywords: type 1 diabetes; age of diagnosis; sex; parental origin of alleles

Neurogenetics Section, Clarke Division, Centre for Addiction and Mental Health, Department of Psychiatry, University of Toronto, 250 College Street, Toronto, Ontario M5T 1R8, Canada

A D Paterson

A Petronis

Correspondence to: Dr Paterson

Revised version received 25 October 1999

Accepted for publication

27 October 1999 effects, or the result of type 1 error. ${ }^{17}$ Low penetrance and a high degree of genetic locus heterogeneity (when different genes confer susceptibility in different families) cannot be excluded in type 1 diabetes.

Several approaches have been used to reduce locus heterogeneity. Post hoc locus heterogeneity analysis can be useful to separate families that are linked to a specific locus from unlinked families, but this approach can only identify clearly linked (or unlinked) families when each family is sufficiently large. This strategy has also been used for small families; however, it is not possible to determine with any certainty which families are truly linked or unlinked to a particular locus. Another approach to reducing heterogeneity involves analysing subgroups based on pathogenic features, such as the presence of specific antibodies, ${ }^{8}$ or other biological measures. The power derived from dividing the sample into subgroups clearly depends on the choice of appropriate bases for splitting the data.

A third approach to reducing locus heterogeneity, searching for epistasis, has already been performed in one of the genome scans for type 1 diabetes as part of the primary analyses. ${ }^{2}$ Affected sib pair families were subdivided based on (1) sharing of either two or (2) one or no HLA haplotypes, whether the sibs were (3) DR3/DR4, (4) DR4/not DR4, or (5) DR3/not DR4, or (6) sharing of high or (7) low risk alleles at the insulin gene VNTR. Despite studying seven overlapping subgroups, this approach produced only a small number of loci which showed stronger evidence for linkage in certain subgroups. Furthermore, the undertaking of multiple statistical tests on many subgroups of the data leads to concerns about appropriate correction for the multiple analyses. Such extensive sample divisions have been criticised because of the failure to correct for the multiple statistical comparisons performed. $^{5}$ Despite these concerns, heterogeneity analyses are important since they can assist in the identification and fine mapping of loci by providing more significant evidence for linkage, along with narrower confidence intervals regarding the position of the locus. Below we briefly justify the reasons for heterogeneity analyses in type 1 diabetes and provide a number of examples where such analyses appear helpful.

Age of diagnosis. There is a very strong rationale to look for age specific effects in genetic diseases. Attempts to reduce the degree of locus heterogeneity using the criteria of age of diagnosis have been helpful in the fine mapping and identification of a number of human disease genes including $B R C A 1,{ }^{9}$ which is responsible for a proportion of early onset 
Table 1 Description of subgroups of families

\begin{tabular}{lllr}
\hline Basis of division and subgroups & Abbreviation & $\begin{array}{c}\text { No of } \\
\text { families }\end{array}$ \\
\hline All & All families (UK356) & All & \\
Age & Both sibs with onset $\leqslant 10$ years & E & 130 \\
& Both sibs with onset $>10$ years & L & 95 \\
Sex & One sib onset $\leqslant 10$ years and one $>10$ years & D & 131 \\
& Male-male sib pairs & MM & 103 \\
& Female-female sib pairs & FF & 80 \\
& Mixed sex sib pairs & MF & 170 \\
\hline
\end{tabular}

The mean (SD) age of diagnosis in the E group is 5.4 (2.9) years; for the $\mathrm{L}$ group it is 16.7 (5.9) years.

breast cancer, and PS1 in early onset Alzheimer's disease. ${ }^{10}$ Genetic determination of age at diagnosis in type 1 diabetes is suggested by data from over 400 pairs of twins. ${ }^{11}{ }^{12}$ In the NOD mouse model of type 1 diabetes, Idd4 is linked to early onset of diabetes. ${ }^{1314}$ Using age at diagnosis as the basis for heterogeneity in the data from Mein et $a l^{2}$ we have shown that this approach provides evidence for novel susceptibility loci for type 1 diabetes. Sib pairs both diagnosed $>10$ years of age show linkage to the region encompassing the Huntington's disease locus (4p16.3), while linkage of sib pairs with onset both $\leqslant 10$ years of age show linkage to the locus for Wolfram syndrome (Paterson and Petronis, unpublished observation).

Sex of affected sib pairs. Sex differences in the age specific incidence of type 1 diabetes have been described. ${ }^{15}$ Molecular studies have shown differences in the evidence for linkage of affected males and females to regions on the autosomes for hypertension, ${ }^{16}$ osteoarthritis,${ }^{17}$ and alcoholism. ${ }^{18}$ Moreover, experimental animal models of a number of complex traits have identified loci that show evidence for linkage to affected offspring of only one gender, including hypertension, ${ }^{19}$ stroke, ${ }^{20}$ alcohol preference, ${ }^{21}$ obesity, ${ }^{22}{ }^{23}$ nociception, ${ }^{24}{ }^{25}$ insulitis, ${ }^{26}$ arthritis, ${ }^{27}$ and glomerulonephritis. ${ }^{28}$ At IDDM1, significantly more males with type 1 diabetes have DR3/not DR4 than females. ${ }^{29}$ Using data provided by Dr Todd, ${ }^{2}$ we have previously reported that linkage to IDDM9 (chromosome 3q) was observed in female-female affected sib pairs, but not male sib pairs. ${ }^{30}$ Although the reasons for such differences are not clear, they may, in part, be because of genetic effects, rather than resulting from differential effects of hormones.

Parental origin of shared alleles. The differential penetrance of genes depending on their parental origin has been observed in a number of Mendelian disorders where it is termed genomic imprinting. ${ }^{31}$ Evidence for parental origin effects have been described at IDDM1 in type 1 diabetes, but these findings are controversial. $^{32}$ At the insulin gene locus in both type 1 diabetes ${ }^{33} 34$ and polycystic ovarian syndrome, ${ }^{35}$ clear parental origin effects have been described. Molecular parental origin effects have been described in a number of other complex diseases, including coeliac disease, ${ }^{36}$ psoriasis, ${ }^{37}$ IgA deficiency, ${ }^{38}$ bipolar affective disorder, ${ }^{39-42}$ and asthma. ${ }^{43}{ }^{44} \mathrm{~A}$ possible mechanism for differential parental effects of loci may arise from the observation that a number of genes display differences in susceptibility to mutation, depending on the parental origin of the gene. ${ }^{45}{ }^{46}$ Similarly, in "genomic disorders", parent of origin effects have been described. ${ }^{47}$ We have previously hypothesised that analysis of sharing of maternal and paternal alleles separately may be useful for complex traits and have provided such evidence for some loci for type 1 diabetes. ${ }^{32}$

Based on the encouraging results of heterogeneity analyses presented above, we propose that further heterogeneity analyses may lead to additional insights into the genetics of type 1 diabetes and use data from a large genome scan for type 1 diabetes to illustrate this. ${ }^{2}$ Our rationale was to assess evidence for heterogeneity based on a number of factors which may be related to risk for type 1 diabetes.

\section{Methods}

Pedigree and genotyping data for 351 markers from the autosomes of 356 affected sib pair families ${ }^{2}$ ascertained in the UK by the British Diabetic Association Warren repository ${ }^{48}$ and made available by Dr Todd (http:// diesel.cimr.cam.ac.uk/todd/) were used. These include 93 families from the original "UK96" genome scan, ${ }^{3}$ as well as 263 families. $^{2}$ Age of onset data were provided by Charles Mein. Marker genotypes were scored uniquely in each family using a four allele system, numbering the alleles observed in each family 1-4. Since we wanted to ensure that none of our results was dependent on possible misspecification of marker allele frequencies, we decided to base our analysis only on allele sharing that could be inferred to be identical by descent (IBD). Elsewhere, it has been pointed out that IBD analysis may tend to have reduced power compared to analysis which uses allele frequencies, ${ }^{49}$ because of the higher probability of being able to determine that 0 alleles are shared compared to 1 allele shared. However, in this paper we prefer the IBD sharing approach since it is robust. We used sib_ibd from ASPEX v 1.17 (Hinds and Risch, 1996) to perform this. This analysis provides separate counts of shared maternal and paternal alleles, as well as the combined maternal and paternal sharing. The number of alleles in the combined analysis in some cases is greater than the sum in each subgroup, because some alleles can be shared, but their parental origin is not known. We performed genome wide linkage analysis in each of the subgroups; more details about the characteristics of each subgroup are provided in table 1 . The \%IBD shared between groups at particular markers was compared using a $2 \times$ 2 contingency table.

Because we generated six partially overlapping subgroups of the total data, correction for multiple tests cannot be performed using straightforward methods (for example, Bonferroni). In addition, since little is known about the molecular genetics of type 1 diabetes, our preliminary findings can be considered to be exploratory in nature, and can be used to generate specific hypotheses that can be tested in independent samples. Studies of complex traits 


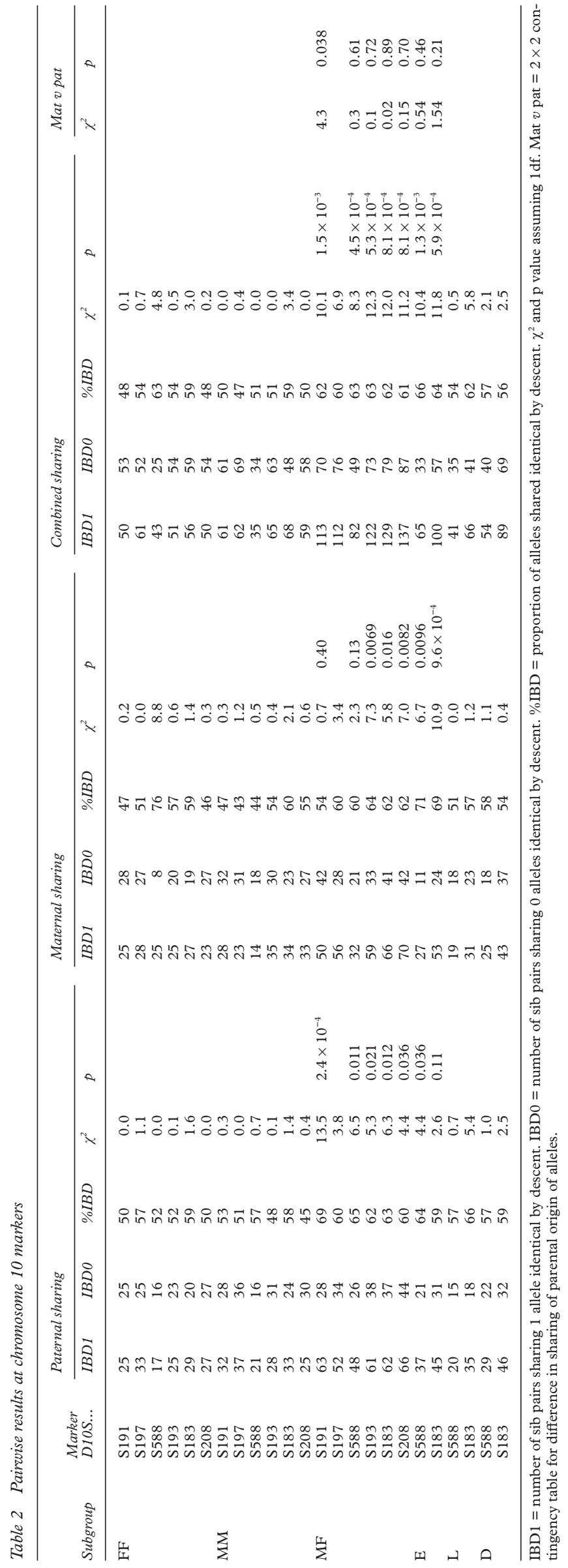

run the gauntlet of trying to find a balance between using a too stringent significance criterion and missing interesting results, or using a too liberal criterion and reporting many results which may turn out to be type 1 errors. ${ }^{50}{ }^{51}$ In an attempt to control the type 1 error in our study, we decided to present only results where markers produced $\chi^{2}>10$ $(p<0.0016)$ in any subgroup. Such a criterion is in agreement with "putative linkage" $(\mathrm{p}<0.0010) .^{51}$

\section{Results}

No marked differences between the subgroups as regards allele sharing at microsatellite markers around the HLA locus on chromosome $6 \mathrm{p} 21$ were observed. However, it must be noted that specific HLA haplotypes and genotypes were not available for this study. Markers D16S3040 and D19S226 produced $\chi^{2}>10$ for all families, but no subgroup produced $\chi^{2}>10$ and these also will not be discussed further. The TH locus, close to IDDM2, also produced excess sharing of alleles in the whole sample (IBD $=57 \%, \chi^{2}=11.3$ ), and elsewhere we have previously shown that this derives predominantly from excess sharing of maternal alleles $\left(\mathrm{IBD}=61 \%, \chi^{2}=12.5\right)$ and not paternal (IBD $=54 \%, \chi^{2}=1.6^{32}$ ); however, no marked differences in the linkage of subgroups were noted (data not shown). The results from all other markers reaching our inclusion criterion are presented in tables 2 and 3 .

Table 2 presents positive results from markers in the centromeric region of chromosome 10 , encompassing IDDM10, and the results are not straightforward. At D10S588 there appears to be linkage in FF pairs; they show excess sharing of maternal alleles (IBD $=76 \%$, $\chi^{2}=8.8$ ), but this does not reach our critical level. In addition, mixed sex pairs show evidence for linkage throughout this region, with generally similar sharing of paternal and maternal alleles. Also, the linkage to markers in this region appears predominantly in $\mathrm{E}$ pairs rather than $\mathrm{L}$ or $\mathrm{D}$ pairs.

At D3S1279 (IDDM9), it appears that the evidence for linkage derives predominantly from families with affected female sibs and that the allele sharing in these families is predominantly of maternal origin (table 3). At D4S412 (4p16.3) evidence for linkage appears in the late onset group, and the sharing at this marker is predominantly of maternal alleles (table 3). Finally, in the D group, there was marked excess non-sharing of alleles at D4S430 (IBD $=34 \%$, $\chi^{2}=18.1$, table 3 ). Both the $\mathrm{E}$ and $\mathrm{L}$ onset groups show no deviation from the null hypothesis (IBD $=48 \%$ and $42 \%$, respectively). Thus, at D4S430, the majority of the excess non-sharing at D4S430 derived from those pairs where one was diagnosed before and after the age of 10 years. At the FGF3 locus on chromosome 11q13 (IDDM4), excess sharing was observed predominantly arising from mixed sex pairs, while there was no evidence for linkage from same sex pairs (table 3 ). 


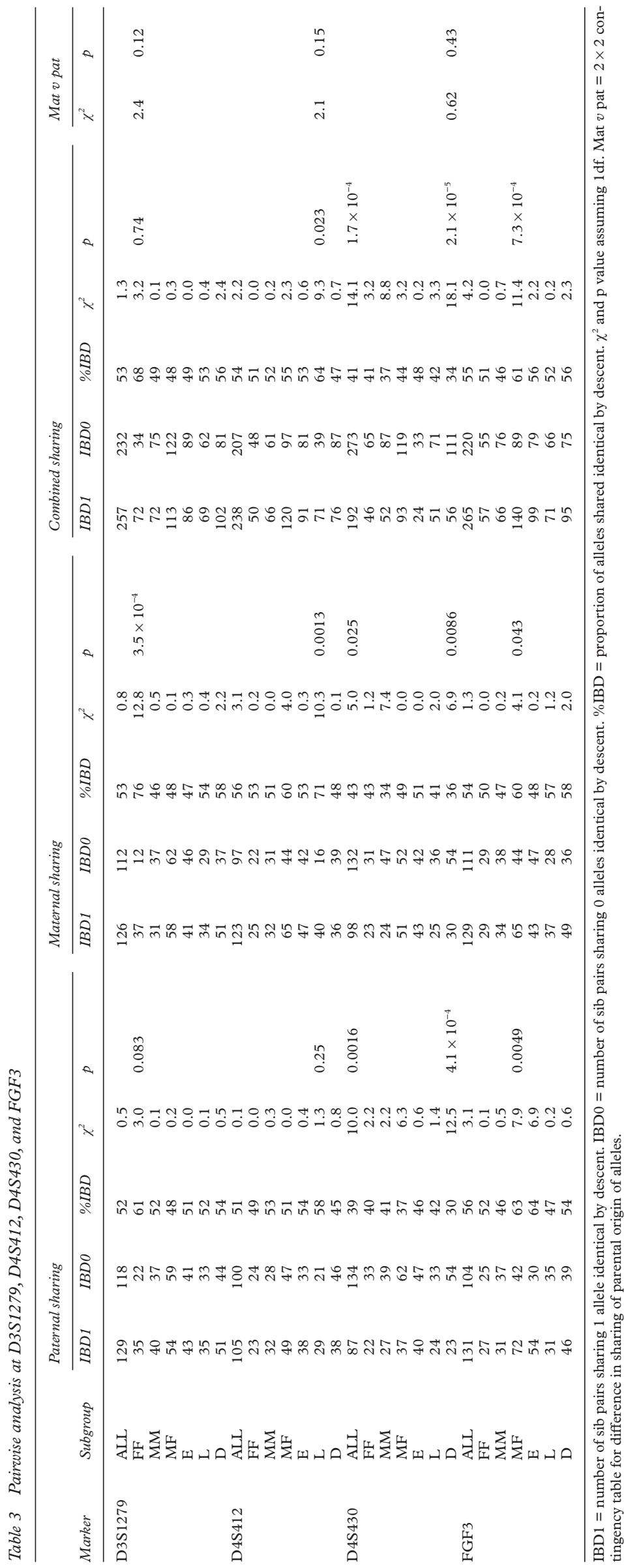

\section{Discussion}

Here we present a detailed heterogeneity analysis of a large genome scan for type 1 diabetes susceptibility loci, using sex of affected sibs and age of diagnosis as bases for our heterogeneity analyses. We also provide the degree of sharing of maternal and paternal alleles separately. Using a similar significance criteria to those suggested elsewhere, ${ }^{50}{ }^{51}$ we found nine chromosomal regions which meet our significance criteria. Confirmation of the results from the exploratory results presented here are clearly required.

Although we observed no significant differences in allele sharing at markers close to HLA, this does not contradict previous findings since HLA genotypes were not available in these data. Age related differences in HLA haplotypes have been observed in type 1 diabetes, ${ }^{52}{ }^{53}$ while parental origin effects at HLA have not been observed consistently. ${ }^{32}$ Definitive interpretation of differences in linkage of maternal and paternal meioses in pairwise linkage analysis requires a high density of markers to distinguish effects of sex specific genetic maps from a locus showing genomic imprinting. ${ }^{32}$ The differences in parental allele sharing at D3S1279 and D4S412 may be solely because of differences in the sex specific genetic distances between the marker and locus. For example, the markers flanking D3S1279 are greater than $10 \mathrm{cM}$ either side of D3S1279 in both the male and female genetic maps. The sharing of maternal alleles in late onset sib pairs at D4S412 (chromosome $4 \mathrm{p} 16.3$ ) maps very close to the Huntington's disease locus, for which clinical and molecular parental origin effects have been described. ${ }^{545}$ According to the Genetic Location Database, ${ }^{56}$ D4S412 maps $2 \mathrm{cM}$ in both the male and female genetic maps from the Huntington's disease gene $(H D)$.

The excess non-sharing of alleles at D4S430 on chromosome $4 \mathrm{q}$ in sib pairs with discordant ages of onset is interesting since a previous analysis of part of the data studied here (UK96) reported that the extent of nonsharing at D4S430 (32\%) was nearly as deviant from the null hypothesis as the excess sharing at HLA $(73 \%) .{ }^{3}$ However, attempts to replicate the excess non-sharing in two separate family sets (UK102 and US84) did not produce excess non-sharing, and the finding in the UK96 was explained as probably the result of a type 1 error. ${ }^{3}$ Here we observe that the excess non-sharing derives predominantly from pairs with one sib diagnosed at age $\leqslant 10$ years and one sib diagnosed older than 10 years of age ("discordant" for age of diagnosis). Excess non-sharing of alleles is expected when discordant sib pairs (one affected, one unaffected) are studied, and an example of this is the $A D H 3$ locus in alcoholism. Deviation from the null hypothesis was greater in pairs discordant for alcoholism ( $\mathrm{IBD}=46 \%)$ compared to concordant affected or concordant unaffected sib pairs $\left(\mathrm{IBD}=50 \%\right.$ and $51 \%$, respectively $\left.{ }^{57}\right)$. The excess non-sharing in discordant sib pairs near the $A D H 3$ locus has also been observed in another study of alcoholism. ${ }^{58}$ In relation to the 
type 1 diabetes findings at D4S430, it is of note that there is evidence for linkage of type 2 diabetes in Mexican American ${ }^{59}$ to markers which map to within $10 \mathrm{cM}$ of D4S430 in the sex averaged genetic map. ${ }^{60}$ In this study, data from unaffected sibs were not studied, but genotype data from unaffected subjects may assist in mapping the locus near D4S430.

The predominant findings at markers on chromosome 10 (IDDM10) are that there is greater sharing in opposite sex than same sex pairs. However, this situation does not occur throughout the IDDM10 region; at D10S183 (table 2) $\mathrm{MM}$ and FF pairs both share 59\% IBD, which is not significantly different from MF pairs which share $62 \%$. According to the primary analysis, ${ }^{2}$ the second strongest linkage (after HLA) was to a region on chromosome 10, at IDDM10, with an MLS of 4.7. However, the shape of the multipoint linkage plot appears rather skewed (http://www.well.ox.ac.uk/ chaz/ PICTURES/c10tot.GIF), although information content is relatively constant across the whole region (http://krusty.cimr.cam.ac.uk/ $\sim$ chaz/PICTURES/c10i.GIF). The shape of the multipoint plot differs from that which one would expect for a true peak reflecting a single underlying susceptibility locus. ${ }^{61}$ Possible explanations for this include the presence of more than one susceptibility locus in this region, and there are precedents for this from the NOD mouse model of type 1 diabetes, ${ }^{62} 63$ a mouse model of systemic lupus erythematosus, ${ }^{28}$ as well as type 1 diabetes in humans near IDDM $1 .{ }^{64}$ Our earlier analysis of the whole data set on chromosome 10 using parental sex specific multipoint analysis provided some evidence that there may be two distinct loci on chromosome 10 for type 1 diabetes, one at D10S191 and a second at D10S183, ${ }^{32}$ and these two markers are $23 \mathrm{cM}$ apart in the sex averaged genetic map. ${ }^{60}$ Furthermore, at the IDDM10 region, there is more significant evidence for linkage in sib pairs with disease onset less than or equal to 10 years of age, compared to those sib pairs both diagnosed after the age of 10 (table 2). Despite these findings, we have not been able clearly to localise loci and their effects within the chromosome 10 region. Similarly, greatest sharing at FGF3 (chromosome 11q13, IDDM4) was observed in opposite sex sib pairs. A number of previous reports have provided evidence for linkage to IDDM4 without differentiating by sex of affected sibs. ${ }^{45-67}$ The lower degree of allele sharing in same sex pairs at both IDDM10 and IDDM4 may be the result of type 2 error; however, it is difficult to speculate about mechanisms which may produce excess sharing in opposite rather than same sex pairs.

Over the last 10 years, a number of developments have made affected sib pair (ASP) studies the mainstay of linkage studies in complex diseases. For the main part, the reasons behind such a shift are compelling: larger numbers of families are available, results depend less on diagnosis of critical people, a lower probability of bilineal transmission at susceptibility loci, and the fact that genetic parameters are not required. Despite this, families with just affected sib pairs may represent a diluted sample of "genetic" families compared to larger multiplex families, with some affected sib pairs possibly resulting from environmental factors.

Although the results presented here are interesting, the data in this study are based on a relatively heterogeneous population. Two further approaches may additionally assist in reducing locus heterogeneity. First, the use of categorical "affected" or "unaffected" phenotypes may not be particularly powerful for complex diseases and, instead, biological markers of subgroups of disease may be more useful for genetic studies, since it is likely that the genes underlying such traits are fewer and the effects of at least some loci are larger. Secondly, the use of genetic isolates has not been exploited to a great extent in studies of type 1 diabetes. One exception has been the study of a large Bedouin Arab family that features a high degree of inbreeding. ${ }^{6}$ Such families may provide strong evidence for linkage to only a single locus, but the critical haplotype is usually large. Based on our results, we concluded that heterogeneity analysis may be useful to dissect the genetic architecture of complex human diseases.

The raw genotyping data ${ }^{2}$ used in this analysis are available from Dr Todd's web site: http://diesel.cimr.cam.ac.uk/todd/ We thank Dr James Kennedy for his assistance, Drs John Todd and Charles Mein for making their genotyping data available, and Charles Mein for making their genotyping data available, and
Cathy Spegg for help with data management. ADP is a Fellow of the Medical Research Council of Canada, AP is an OMHF New Investigator and is supported by NARSAD.

1 She JX, Marron MP. Genetic susceptibility factors in type 1 diabetes: linkage, disequilibrium and functional analyses. Curr Opin Immunol 1998;10:682-9.

2 Mein CA, Esposito L, Dunn MG, et al. A search for type 1 diabetes susceptibility genes in families from the United Kingdom. Nat Genet 1998;19:297-300.

3 Davies JL, Kawaguchi Y, Bennett ST, et al. A genome-wide search for human type 1 diabetes susceptibility genes. Nature 1994;371:130-6.

4 Hashimoto L, Habita C, Beressi JP, et al. Genetic mapping of a susceptibility locus for insulin-dependent diabetes mellitus on chromosome 11q. Nature 1994;371:161-4.

5 Concannon P, Gogolin-Ewens KJ, Hinds DA, et al. A second-generation screen of the human genome for susceptibility to insulin-dependent diabetes mellitus. Nat Genet 1998;19:292-6.

6 Verge CF, Vardi P, Babu S, et al. Evidence for oligogenic nheritance of type 1 diabetes in a large Bedouin Arab family. F Clin Invest 1998;102:1569-75.

7 Lernmark A, Ott J. Sometimes it's hot, sometimes it's not. Nat Genet 1998;19:213-14

8 Gorus FK. Diabetes registries and early biological markers of insulin-dependent diabetes mellitus. Belgian Diabetes Registry. Diabetes Metab Rev 1997;13:247-74.

9 Hall JM, Lee MK, Newman B, et al. Linkage of early-onset familial breast cancer to chromosome 17q21. Science 1990; 250:1684-9.

10 Schellenberg GD, Bird TD, Wijsman EM, et al. Genetic linkage evidence for a familial Alzheimer's disease locus on chromosome 14. Science 1992;258:668-71.

11 Kyvik KO, Green A, Beck-Nielsen H. Concordance rates of insulin dependent diabetes mellitus: a population based insulin dependent diabetes mellitus: a population

12 Fava D, Gardner S, Pyke D, Leslie RD. Evidence that the age at diagnosis of IDDM is genetically determined. age at diagnosis of IDDM
Diabetes Care 1998;21:925-9.

13 Todd JA, Aitman TJ, Cornall RJ, et al. Genetic analysis of autoimmune type 1 diabetes mellitus in mice. Nature 1991; 351:542-7.

14 Ghosh S, Palmer SM, Rodrigues NR, et al. Polygenic control of autoimmune diabetes in nonobese diabetic mice. Nat Genet 1993;4:404-9.

15 Karvonen M, Pitkaniemi M, Pitkaniemi J, Kohtamaki K, Tajima N, Tuomilehto J. Sex difference in the incidence of insulin-dependent diabetes mellitus: an analysis of the recent epidemiological data. World Health Organization . 275-91.

16 O'Donnell CJ, Lindpaintner K, Larson MG, et al. Evidence for association and genetic linkage of the angiotensinconverting enzyme locus with hypertension and blood pressure in men but not women in the Framingham Heart pressure in men but not women in
Study. Circulation 1998;97:1766-72. 
17 Chapman K, Mustafa Z, Irven C, et al. Osteoarthritissusceptibility locus on chromosome 11 , detected by linksusceptibility locus on chromosome 11
age. Am f Hum Genet 1999;65:167-74.

18 Paterson AD, Petronis A. Sex-based linkage analysis of alcoholism. Genet Epidemiol 1999;17S:289-94.

19 Clark JS, Jeffs B, Davidson AO, et al. Quantitative trait loci in genetically hypertensive rats. Possible sex specificity. Hypertension 1996;28:898-906.

20 Rubattu S, Volpe M, Kreutz R, Ganten U, Ganten D, Lindpaintner K. Chromosomal mapping of quantitative trai loci contributing to stroke in a rat model of complex human disease. Nat Genet 1996;13:429-34.

21 Melo JA, Shendure J, Pociask K, Silver LM. Identification of sex-specific quantitative trait loci controlling alcohol preference in C57BL/6 mice. Nat Genet 1996:13:147-53.

22 Taylor BA, Phillips SJ. Obesity QTLs on mouse chromosomes 2 and 17. Genomics 1997;43:249-57.

23 Kovacs P, Voigt B, Kloting I. Congenic strain confirms putative quantitative trait locus for body weight in the rat. putative quantitative trait locu.

24 Mogil JS, Richards SP, O'Toole LA, Helms ML, Mitchell SR, Belknap JK. Genetic sensitivity to hot-plate nociception in DBA/2J and C57BL/6J inbred mouse strains: possible sex-specific mediation by delta2-opioid receptors. Pain 1997; 70:267-77.

25 Mogil JS, Richards SP, O'Toole LA, et al. Identification of a sex-specific quantitative trait locus mediating nonopioid stress-induced analgesia in female mice. 7 Neurosci 1997; 17:7995-8002

26 Melanitou E, Joly F, Lathrop M, Boitard C, Avner P. Evidence for the presence of insulin-dependent diabetesassociated alleles on the distal part of mouse chromosome 6. Genome Res 1998;8:608-20.

27 Vingsbo-Lundberg C, Nordquist N, Olofsson P, et al. Genetic control of arthritis onset, severity and chronicity in a model for rheumatoid arthritis in rats. Nat Genet 1998;20:401-4.

28 Morel L, Mohan C, Yu Y, et al. Multiplex inheritance of component phenotypes in a murine model of lupus. Mamm Gemome 1999;10:176-81.

29 Cucca F, Goy JV, Kawaguchi Y, et al. A male-female bias in type 1 diabetes and linkage to chromosome $\mathrm{Xp}$ in $\mathrm{MHC}$ HLA-DR3-positive patients. Nat Genet 1998;19:301-2

30 Paterson AD, Petronis A. Sex of affected sibpairs and genetic linkage to type 1 diabetes. Am f Med Genet 1999;84:15-19

31 Sapienza C, Hall JG. Genetic imprinting in human disease. In :Scriver CR, Beaudet AL, Sly WS, Valle D, eds. The metabolic and molecular bases of inherited disease. Vol 1. New York: McGraw-Hill, 1995:437-58.

32 Paterson AD, Naimark DM, Petronis A. The analysis of parental origin of alleles may detect susceptibility loci for complex disorders. Hum Hered 1999;49:197-204.

33 Bennett ST, Lucassen AM, Gough SC, et al. Susceptibility to human type 1 diabetes at IDDM2 is determined by tandem repeat variation at the insulin gene minisatellite locus. Nat Genet 1995;9:284-92.

34 Bennett ST, Wilson AJ, Esposito L, et al. Insulin VNTR allele-specific effect in type 1 diabetes depends on identity of untransmitted pater

35 Bennett ST, Todd JA, Waterworth DM, Franks S, McCarthy MJ. Association of insulin gene VNTR polymorphism with polycystic ovary syndrome. Lancet 1997;349 1771-2.

36 Petronzelli F, Bonamico M, Ferrante P, et al. Genetic contribution of the HLA region to the familial clustering of coeliac disease. Ann Hum Genet 1997;61:307-17.

37 Burden $\mathrm{AD}$, Javed S, Bailey M, Hodgins M, Connor M, Tillman D. Genetics of psoriasis: paternal inheritance and a locus on chromosome 6p. F Invest Dermatol 1998;110. 958-60.

38 VoÍlechovský I, Webster ADB, Plebani A, Hammarström L. Genetic linkage of IgA deficiency to the major histocompatibility complex: evidence for allele segregation distortion, parent-of-origin penetrance differences, and the role of anti-IgA antibodies in disease predisposition. Am f Hum of anti-IgA antibodies in

39 Stine OC, Xu J, Koskela R, et al. Evidence for linkage of bipolar disorder to chromosome 18 with a parent- of-origin effect. Am F Hum Genet 1995;57:1384-94.

40 Gershon ES, Badner JA, Detera-Wadleigh SD, Ferraro TN Berrettini WH. Maternal inheritance and chromosome 18 allele sharing in unilineal bipolar illness pedigrees. $\mathrm{Am} f$ Med Genet 1996;67:202-7.

41 McMahon FJ, Hopkins PJ, Xu J, et al. Linkage of bipolar affective disorder to chromosome 18 markers in a new pedigree series. Am F Hum Genet 1997;61:1397-404

42 Nothen MM, Cichon S, Rohleder H, et al. Evaluation of linkage of bipolar affective disorder to chromosome 18 in a sample of 57 German families. Mol Psychiatry 1999;4:7684.
43 Daniels SE, Bhattacharrya S, James A, et al. A genome-wide search for quantitative trait loci underlying asthma. Nature 1996;383:247-50

44 Mao XO, Shirakawa T, Sasaki S, Enomoto T, Morimoto K, Hopkin JM. Maternal inheritance of atopy at the Fc epsilon RI beta locus in Japanese sibs. Hum Hered 1997;47:178-80.

45 Vogel F, Rathenberg R. In: Harris H, Hirschhorn K, eds. Advances in human genetics. Vol 5. New York: Plenum Press, 1985:223-318.

46 Sapienza C. Parental origin effects, genome imprinting, and sex-ratio distortion: double or nothing? Am f Hum Genet 1994;55:1073-5.

47 Lupski JR. Genomic disorders: structural features of the genome can lead to DNA rearrangements and human disease traits. Trends Genet 1998;14:417-22.

48 Bain SC, Todd JA, Barnett AH. The British Diabetic Association - Warren repository. Autoimmunity 1990;7:83-

49 Holmans P. Affected sib-pair methods for detecting linkage to dichotomous traits: review of the methodology. Hum Biol 1998;70:1025-40

50 Lander E, Kruglyak L. Genetic dissection of complex traits: guidelines for interpreting and reporting linkage results. Nat Genet 1995;11:241-7.

51 Rao DC. CAT scans, PET scans, and genomic scans. Genet Epidemiol 1998;15:1-18.

52 Valdes AM, Thomson G, Erlich HA, Noble JA. Association between type 1 diabetes age of onset and HLA among sibling pairs. Diabetes 1999;48:1658-61.

53 Graham J, Kockum I, Sanjeevi CB, et al. Negative association between type 1 diabetes and HLA $\mathrm{DQB} 1^{\star} 0602-\mathrm{DQA} 1^{\star} 0102$ is attenuated with age at onset. Swedish Childhood Diabetes Study Group. Eur 7 Immunogenet 1999;26:117-27.

54 Ridley RM, Frith CD, Crow TJ, Conneally PM. Anticipation in Huntington's disease is inherited through the male line but may originate in the female. F Med Genet 1988;25: 589-95.

55 Zuhlke C, Riess O, Bockel B, Lange H, Thies U. Mitotic stability and meiotic variability of the (CAG)n repeat in the Huntington disease gene. Hum Mol Genet 1993;2:2063-7.

56 Collins A, Frezal J, Teague J, Morton NE. A metric map of humans: 23,500 loci in 850 bands. Proc Natl Acad Sci USA 1996;93:14771-5: http://cedar.genetics.soton.ac.uk/ public_html/

57 Reich T, Edenberg HJ, Goate A, et al. Genome-wide search for genes affecting the risk for alcohol dependence. $A m \mathcal{F}$ Med Genet 1998;81:207-15.

58 Long JC, Knowler WC, Hanson RL, et al. Evidence for genetic linkage to alcohol dependence on chromosomes 4 and 11 from an autosome-wide scan in an American Indian population. Am f Med Genet 1998;81:216-21.

59 Duggirala R, Blangero J, Almasy L, et al. Linkage of type 2 diabetes mellitus and of age at onset to a genetic location on chromosome 10q in Mexican Americans. Am f Hum Genet 1999;64:1127-40.

60 Broman KW, Murray JC, Sheffield VC, White RL, Weber JL. Comprehensive human genetic maps: individual and sex-specific variation in recombination. Am $\mathcal{F}$ Hum Genet 1998;63:861-9.

61 Terwilliger JD, Shannon WD, Lathrop GM, et al. True and false positive peaks in genomewide scans: applications of length-biased sampling to linkage mapping. Am f Hum Genet 1997;61:430-8.

62 Podolin PL, Denny P, Lord CJ, et al. Congenic mapping of the insulin-dependent diabetes (Idd) gene, Idd10, localizes two genes mediating the Idd 10 effect and eliminates the candidate Fcgr1. F Immunol 1997;159:1835-43.

63 Podolin PL, Denny P, Armitage N, et al. Localization of two insulin-dependent diabetes (Idd) genes to the Idd 10 region on mouse chromosome 3. Mamm Genome 1998;9:283-6.

64 Lie BA, Todd JA, Pociot F, et al. The predisposition to type 1 diabetes linked to the human leukocyte antigen complex includes at least one non-class II gene. Am f Hum Genet 1999;64:793-800

65 Field LL, Tobias R, Magnus T. A locus on chromosome 15 q26 (IDDM3) produces susceptibility to insulindependent diabetes mellitus. Nat Genet 1994;8:189-94.

66 Luo DF, Buzzetti R, Rotter JI, et al. Confirmation of three susceptibility genes to insulin-dependent diabetes mellitus: IDDM4, IDDM5 and IDDM8. Hum Mol Genet 1996;5: 693-8.

67 Nakagawa Y, Kawaguchi Y, Twells RC, et al. Fine mapping of the diabetes-susceptibility locus, IDDM4, on chromosome 11q13. Am f Hum Genet 1998;63:547-56. 